\title{
Correction to: Effect of various refining processes for Kenaf Bast non-wood pulp fibers suspensions on heat transfer coefficient in circular pipe heat exchanger
}

\author{
Syed Muzamil Ahmed ${ }^{1}$ (D) - S. N. Kazi ${ }^{1}$ Ghulamullah Khan ${ }^{5} \cdot \operatorname{Rad~Sadri~}^{1}$ • \\ Mahidzal Dahari $^{2}$ • M. N. M. Zubir ${ }^{1}$ • M. Sayuti ${ }^{1} \cdot$ Pervaiz Ahmad $^{4} \cdot$ Rushdan Ibrahim $^{3}$
}

Published online: 11 November 2017

(C) Springer-Verlag GmbH Germany 2017

\section{Correction to: Heat Mass Transfer}

https://doi.org/10.1007/s00231-017-2176-3

The name of the first author is incorrect. It should be Syed Muzamil Ahmed, not Muzamil Ahmed Syed.

The original article was corrected.

The online version of the original article can be found at https://doi.org/ 10.1007/s00231-017-2176-3.

Syed Muzamil Ahmed

syed.ma@hotmail.com

$\bowtie$ S. N. Kazi

salimnewaz@um.edu.my

1 Department of Mechanical Engineering, Faculty of Engineering, University of Malaya, 50603 Kuala Lumpur, Malaysia

2 Department of Electrical Engineering, Faculty of Engineering, University of Malaya, 50603 Kuala Lumpur, Malaysia

3 Pulp and Paper Branch, Forest Research Institute Malaysia (FRIM), 52109 Kepong, Selangor, Malaysia

4 Department of Physics, Abbottabad University of Science and Technology, 22500 Havelian KP, Pakistan

5 Department of Chemical Engineering, Balochistan University of Information Technology, Engineering and Management Sciences, 87300 Quetta, Pakistan 